\title{
Ammonium uptake and growth models in marine diatoms: Monod and Droop revisited
}

\author{
W. G. Sunda* ${ }^{*}$ K. W. Shertzer, D. R. Hardison \\ Center for Coastal Fisheries and Habitat Research, NOAA, 101 Pivers Island Road, Beaufort, North Carolina 28516, USA
}

\begin{abstract}
Mathematical models are a useful tool for predicting the responses of marine phytoplankton to changes in nutrient inputs and other environmental factors. Two modeling approaches Monod and Droop - have been traditionally used. These 2 model types were fitted to empirical data for specific growth rate, cellular $\mathrm{N}$ :C ratio, cellular ammonium uptake rate, and ammonium concentration measured in $\mathrm{N}$-limited cyclostats at different dilution rates and in nutrient-saturated batch cultures. The modeled data were for a small, fast-growing coastal diatom Thalassiosira pseudonana ( 4.5 $\mu \mathrm{m}$ diameter) and for a larger, slower growing diatom $T$. weissflogii ( 11 $\mu \mathrm{m}$ diameter) cultured in seawater medium at $20^{\circ} \mathrm{C}$ and $14 \mathrm{~h} \mathrm{~d}^{-1}$ of light. The observed data did not conform well to the classic Monod equation, but could be fit to a modification of this equation in which the maximum growth rate was assigned a value higher than the observed maximum rate. Likewise, data for cellular $\mathrm{N}$ uptake rate versus ammonium concentration did not conform well to the standard saturation equation, but could be fit to a modification of the equation in which the maximum uptake rate was set above the empirically measured value and the $x$-intercept was shifted from the origin to a finite positive value. Both modified models accurately fit the observed steady-state relationships between ammonium concentrations and specific growth rates of the 2 species. However, the 2 models showed different transient dynamics in response to a change in the concentration of inflowing nutrients in time-course simulations. Such differences suggest that the choice between Droop and Monod approaches, when used as part of larger food web models, could lead to widely divergent predictions of algal blooms and other nonequilibrium dynamics of ecosystems.
\end{abstract}

KEY WORDS: Ammonium · Model $\cdot$ Nutrient uptake $\cdot$ Growth rate $\cdot$ Phytoplankton $\cdot$ Diatom Monod · Droop

\section{INTRODUCTION}

Changes in global climate, eutrophication of coastal waters, and increased incidence of harmful algal blooms has heightened our need for predictive models of planktonic ecosystem dynamics. At their core, these models must be able to simulate and predict causative relationships among important controlling factors and rate processes, including concentrations of limiting nutrients, rates of nutrient uptake and associated population growth of phytoplankton species, rates of grazing by zooplankton, and grazer-mediated cycling of nutrients (Mitra \& Flynn 2006, Sunda et al. 2006).

Nutrients typically limit the growth rate and biomass of marine phytoplankton and nitrogen is most com- monly the limiting nutrient in coastal systems and thermally stratified oceanic waters. Consequently, nitrogen availability is an important driving factor in ecosystem dynamics (Ryther 1969, Falkowski \& Raven 1997, Moore et al. 2008). In low-nitrogen waters, ammonium $\left(\mathrm{NH}_{4}{ }^{+}\right)$is often the dominant nitrogen source utilized by phytoplankton, while nitrate, which is energetically more difficult to assimilate, is only a minor source (Harrison et al. 1996, Mulholland \& Lomas 2008). Despite the importance of ammonium in regulating nitrogen supply in nitrogen-limited marine systems, relationships between ammonium concentration and the specific growth rate were unknown until very recently (Sunda \& Hardison 2007) owing to the extreme difficulty of measuring the low ammonium concentrations 
that limit algal growth rate (Goldman \& McCarthy 1978). This uncertainty, in turn, has hampered our ability to accurately predict algal ammonium uptake and growth kinetics in ecosystem models of marine plankton dynamics and nutrient cycling. Indeed, because of the lack of empirical data, previous models used to predict ammonium uptake and growth kinetics at low nutrients have, by necessity, been based on guesswork.

We recently measured steady-state relationships among the specific growth rate of phytoplankton, cellular nitrogen, and ammonium concentration in cyclostat cultures of 2 diatom species (Sunda \& Hardison 2007). These data provide an opportunity, for the first time, to establish accurate predictive mathematical relationships between nitrogen-limited growth rates and ammonium concentrations needed to model plankton dynamics in marine ecosystems.

Historically, 2 basic approaches have been used to mathematically model nutrient limitation in phytoplankton (Goldman 1977). The first, the Monod approach, posits that the specific growth rate $(\mu)$ is a function of the limiting nutrient concentration $(S)$, which in the present case is the ammonium concentration. The functional relationship most frequently used is a growth-saturation function referred to as the Monod equation (Monod 1942):

$$
\mu=\mu_{\max } S /\left(K_{\mu}+S\right)
$$

where $\mu_{\max }$ is the maximum growth rate achieved at high, non-limiting nutrient concentrations and $K_{\mu}$ is the half-saturation constant (the nutrient concentration at which the specific growth rate is half of the maximum). This equation has been widely used to model relationships between specific growth rates and limiting substrate concentrations for a variety of nutrients, including nitrogen (Morel 1987, Frost \& Franzen 1992, Fussmann et al. 2000). The classic Monod chemostat model includes Eq. (1) within coupled differential equations that predict time-dependent changes in concentrations of nutrients and total algal cell carbon $\left(C_{\text {cells }}\right)$ in units of moles per liter of medium (modified from Haefner 2005):

$$
\begin{aligned}
& \frac{\mathrm{d} S}{\mathrm{~d} t}=\delta\left(S_{\mathrm{i}}-S\right)-\mu C_{\text {cells }} Q \\
& \frac{\mathrm{d} C_{\text {cells }}}{\mathrm{d} t}=C_{\text {cells }}(\mu-\delta)
\end{aligned}
$$

where $S_{\mathrm{i}}$ is the nutrient concentration in the input medium and $\delta$ is the dilution rate of the system. The cellular nutrient to carbon ratio $\left(Q_{i}\right.$ nitrogen:carbon in the present study), is assumed to be fixed in the Monod approach.

In the second approach, the cellular nutrient content $(Q)$ is allowed to vary, and the growth rate is modeled as a function of $Q$ using the Droop equation (Droop 1968):

$$
\mu=\mu_{\max }^{\prime}\left(Q-Q_{\min }\right) / Q
$$

In the original Droop equation, $Q$ was defined as the amount of nutrient per cell (Droop 1968). However, when this equation is used in more complex models dealing with carbon acquisition by zooplankton grazers and overall nutrient and carbon cycling, it is more advantageous to define $Q$ as the cellular nutrient to carbon ratio (Sterner \& Elser 2002), as is done here. $Q_{\min }$ in Eq. (3) is the nutrient to carbon ratio at which growth rate is zero and $\mu_{\max }^{\prime}$ is a hypothetical maximum growth rate that is often greater than the actual observed maximum rate. The cellular nutrient to carbon ratio is computed from the relationship between the cellular nutrient uptake rate normalized to cell carbon $(V)$ and the rate of nutrient biodilution from cell growth and division. The Droop modeling approach leads to a system of 3 differential equations that predict time-dependent changes in nutrient concentration (Eq. 4a), Q (Eq. 4b), and total algal carbon per liter of medium (Eq. 4c) in continuous cultures and hypothetical well-mixed basins (Grover 1991, Haefner 2005):

$$
\begin{aligned}
& \frac{\mathrm{d} S}{\mathrm{~d} t}=\delta\left(S_{\mathrm{i}}-S\right)-C_{\text {cells }} V \\
& \frac{\mathrm{d} Q}{\mathrm{~d} t}=V-\mu Q \\
& \frac{\mathrm{d} C_{\text {cells }}}{\mathrm{d} t}=C_{\text {cells }}(\mu-\delta)
\end{aligned}
$$

The nutrient uptake rate is typically modeled with the Michaelis-Menten equation, which has the same form as Eq. (1) (Goldman \& Glibert 1982, Kilham \& Hecky 1988, Haefner 2005):

$$
V=V_{\max } S /\left(K_{V}+S\right)
$$

where $V_{\max }$ is the maximum uptake rate normalized to cell carbon and $K_{V}$ is the half-saturation constant. Although more complicated, the Droop approach is more realistic because growth rate limitation must ultimately depend on the cellular nutrient concentration, which at a given time, is only indirectly related to the nutrient concentration in the external growth medium.

In the present study we used Monod and Droop modeling approaches to construct predictive growth models from experimental steady-state data relating ammonium concentrations, cellular ammonium uptake rates, cellular nitrogen:carbon ratios, and specific growth rates for the centric diatoms Thalassiosira weissflogii (CCMP 1336) and T. pseudonana (clone CCMP 1335), grown in ammonium-limited continuous cultures and nutrient sufficient batch cultures. We found that the empirical data often did not conform to the widely used Monod growth or Michaelis-Menten uptake equations; however, the data could be fit reasonably well to modified forms of these equations. Using these equations in 
time-course simulations of phytoplankton dynamics, we found that the Monod and Droop approaches yielded different predictions of nutrient concentrations, algal nitrogen:carbon ratios, and population dynamics.

\section{MATERIALS AND METHODS}

Culture experiments. Modeled data were obtained from ammonium-limited cyclostat cultures grown in media containing $12 \mu \mathrm{M} \mathrm{NH}_{4} \mathrm{Cl}$ and $2 \mu \mathrm{M} \mathrm{NaH}_{2} \mathrm{PO}_{4}(\mathrm{~N}: \mathrm{P}$ molar ratio $=6$ ) and from nutrient sufficient batch cultures grown in media containing $32 \mu \mathrm{M} \mathrm{NH}_{4} \mathrm{Cl}$ and the same phosphate level ( $\mathrm{N}: \mathrm{P}=16)$, as outlined in Sunda \& Hardison (2007). The cultures were grown at $20^{\circ} \mathrm{C}$ and $100 \mu \mathrm{mol}$ quanta $\mathrm{m}^{-2} \mathrm{~s}^{-1}$ of fluorescent light was provided on a $14 \mathrm{~h}$ light:10 h dark cycle. This light intensity was found to saturate the growth rate of Thalassiosira pseudonana at high ammonium concentrations $(32 \mu \mathrm{M})$ (D. R. Hardison \& W. G. Sunda unpubl. data). Data used in the present modeling study are from previously described experiments (Sunda \& Hardison 2007) and give relationships among specific growth rate, ammonium concentration, cellular $\mathrm{N}: \mathrm{C}$ ratio, and $\mathrm{N}$ uptake rate per mol cell carbon. Data for the first 2 parameters were reported previously (Sunda \& Hardison 2007), but the rest were not. All parameters except growth rate were measured in the middle of the light period; measurement at this time yields values that approximate the mean values observed over the $24 \mathrm{~h}$ diel cycle (Sunda \& Hardison 2007). Total cell volume and average volume per cell were measured with a Beckman-Coulter Multisizer 3 electronic particle counter. Cell N, C, and N:C ratios were measured with a Costech $\mathrm{C}: \mathrm{N}$ Analyzer.

Estimation of model parameters. With data from the cyclostat experiments, we fitted the Monod equation (Eq. 1) and the Droop and Michaelis-Menten equations (Eqs. 3 \& 5) for Thalassiosira weissflogii and T. pseudonana. Parameters were estimated through nonlinear least squares programmed in R (R Development Core Team 2008). Uncertainty in parameter estimates was estimated through empirical bootstrap by resampling residuals (with replacement) and then refitting each function $\mathrm{n}=2000$ times. When fitting the Droop equation, we treated the cellular $\mathrm{N}: \mathrm{C}$ ratio $(Q)$ as the dependent variable because it exhibited less intrinsic relative variability than the specific growth rate $(\mu)$ and had a greater relative measurement error. When fitting the Monod equation, we first fixed $\mu_{\max }$ at the observed maximum growth rate while estimating only $K_{\mu}$, and then repeated the fit with both parameters estimated. Based on data fits to the standard Monod and Michaelis-Menten equations, we modified the forms of these models for improved conformance to data and theory, as described in the 'Results' and 'Discussion'.
Simulations of nutrient and population dynamics. For Thalassiosira weissflogii, we simulated nutrient and population dynamics using both the Monod (Eqs. 1 \& 2) and Droop (Eqs. 3-5) approaches to examine differences in predictions. These simulations gave the predicted system response to a step increase in the nutrient concentration of the influent medium (from $12 \mu \mathrm{M}$ to $24 \mu \mathrm{M}$ ammonium) at both low $\left(\delta=0.2 \mathrm{~d}^{-1}\right)$ and high $\left(\delta=0.6 \mathrm{~d}^{-1}\right)$ dilution rates, as might occur in nature following a rain event. The increase was initiated after the system reached steady state, and we computed the time-dependent changes predicted as the system readjusted to a new steady-state condition. Differences in non-steady-state dynamics predicted by Monod and Droop approaches could be a crucial consideration when building larger multispecies and multi-trophic models. In addition, differences in predicted algal $\mathrm{N}$ :C ratios could be critical in modeling trophic transfer of $\mathrm{C}$ and $\mathrm{N}$ and overall nutrient cycling (Sterner \& Elser 2002, Mitra et al. 2007).

Competition cyclostat experiments. To test a prediction from our nutrient uptake and growth rate models, cyclostat experiments were conducted that examined growth competition between a small (3.6 $\mu$ m diameter) brown tide pelagophyte Aureoumbra lagunensis (clone CCMP 1509) and each of 3 larger (9 to $13 \mu \mathrm{m}$ ) algal species, the diatom Thalassiosira weissflogii (CCMP 1336) and the dinoflagellates Prorocentrum minimum (CCMP 1329) and Amphidinium carterae (CCMP 1314). Based on theory and previous experimental results, A. lagunensis should be able to outgrow the 3 larger species under ammonium growth limitation because of its higher surface to volume ratio and its much higher diffusive flux to the cell surface per unit of cell volume (Sunda \& Hardison 2007).

The competition experiments were conducted in continuous N-limited cyclostat cultures and in semi-continuous, nutrient-sufficient batch cultures using the same procedures, culture chambers, and medium composition as employed in single species experiments (Sunda \& Hardison 2007). The cyclostat culture medium contained $12 \mu \mathrm{M} \mathrm{NH}_{4} \mathrm{Cl}$ and $2 \mu \mathrm{M} \mathrm{NaH}_{2} \mathrm{PO}_{4}(\mathrm{~N}: \mathrm{P}=6)$ and medium used for nutrient-sufficient batch cultures contained $32 \mu \mathrm{M} \mathrm{NH}{ }_{4} \mathrm{Cl}$ and the same phosphate concentration $(\mathrm{N}: \mathrm{P}=16)$. Cells were grown at $25^{\circ} \mathrm{C}$ under the same light conditions as described above. Batch cultures were grown in 1.21 polycarbonate bottles containing 11 of medium. The 11 cyclostat cultures were grown in 21 polycarbonate bottles fitted with large Teflon paddles, as previously described (Sunda \& Hardison 2007). The algal clones used in all experiments were obtained from the Center for the Culture of Marine Phytoplankton (CCMP), Bigelow Laboratory, Maine.

To initiate the competition experiments, cultures of Aureoumbra lagunensis and one of the 3 competing 
species were grown in batch mode at low ammonium concentrations $(12 \mu \mathrm{M})$ in 2 separate cyclostat culture chambers until early stationary phase. At that point the cultures were switched to a continuous-flow mode at a constant dilution rate $\left(0.25 \mathrm{~d}^{-1}\right)$ and the cyclostat cultures were allowed to reach steady state over a period of 1 to $2 \mathrm{wk}$. The competition experiments were initiated by mixing a portion of each of the 2 separate cultures together to form a new, combined cyclostat culture run continuously at the same dilution rate $\left(0.25 \mathrm{~d}^{-1}\right)$ for an $8 \mathrm{~d}$ period.

Total cell volume, cell concentration, and mean volume per cell were measured in triplicate for each species with a Beckman Coulter Multisizer 3 particle counter. Measurements were made daily (except weekends) in the middle of the light period. The sizes of the competing species were sufficiently different to allow nearly complete separation of cell size distribution peaks. The natural log of the total cell volume of each species was regressed against time to yield the net specific growth rate which, when added to the dilution rate $\left(0.25 \mathrm{~d}^{-1}\right)$, yielded the average specific growth rate. In semicontinuous batch cultures, the specific growth rate of each species was determined from linear regression of the natural log of total cell volume versus time after correcting for culture dilution.

\section{RESULTS}

\section{Fits of standard and modified Monod models}

Our data showed a poor fit to the standard Monod equation with $\mu_{\max }$ fixed at its observed empirical value. Best fits to the standard model yielded curves that were above the observed growth rate at low ammonium concentrations and below at high concentrations (Fig. 1A,B). A much better fit was obtained if the maximum growth rate in the Monod equation was allowed to increase above the value observed at growthsaturating ammonium $(32 \mu \mathrm{M})$ (Table 1), a procedure that steepened the predicted curves (Fig. 1C,D). These hypothetical maximum rates were $81 \%$ higher than the actual observed values for Thalassiosira pseudonana and $218 \%$ higher for $T$. weissflogii (Table 1). At ammonium concentrations above $\sim 0.1 \mu \mathrm{M}$, the predicted growth rates exceeded the actual maximum rates. To overcome this difficulty, the predicted growth rates were capped at the observed maximum value at high, growth-saturating ammonium (Fig. 1C,D). Thus a single curve was established that better predicted the observed growth behavior over a wide dynamic range ( 0 to $32 \mu \mathrm{M}$ ).

A better fit of the Monod model could also be obtained if $\mu_{\max }$ was set at the observed nutrient- saturated value, but the curve was shifted to the right on the $x$-axis (Table 1) so that a growth rate of zero occurred at a finite ammonium concentration $\left(S_{\mu}\right)$ :

$$
\mu= \begin{cases}\mu_{\max }\left(S-S_{\mu}\right) /\left(K_{\mu}+S-S_{\mu}\right) & \text { if } S>S_{\mu} \\ 0 & \text { otherwise }\end{cases}
$$

This equation fit well at low ammonium-limited growth rates, but fit more poorly at higher rates (Fig. 1E,F).

Shifting the $x$-intercept to the right (Eq. 6) and also allowing $\mu_{\max }$ to increase above the observed value provided no better fit to the data than a simple increase in $\mu_{\max }$ with no shift in the $x$-intercept (Table 1; Fig. $1 C, D, G, H)$. Thus, nothing further is gained in goodness of fit to these data by the more complex modeling approach. However, experimental data presented in the last section of 'Results' suggest that a growth rate of zero actually occurs for Thalassiosira weissflogii and other species at a finite positive nutrient concentration.

\section{Droop modeling approach}

The Droop modeling approach requires data fit to the Michaelis-Menten and Droop equations (Eqs. 5 \& 3). Fits of the uptake rates to the standard MichaelisMenten equation for the 2 diatoms resulted in estimates of $V_{\max }$ that greatly exceeded empirical values (Fig. 2A,B). For Thalassiosira pseudonana, the estimated $V_{\max }\left(1.16 \mathrm{~mol} \mathrm{~mol}^{-1} \mathrm{C} \mathrm{d}^{-1}\right)$ was 6 times higher than the empirical value at saturating ammonium $\left(0.193 \pm 0.026 \mathrm{~mol} \mathrm{~mol}^{-1} \mathrm{C} \mathrm{d}^{-1}\right)$, obtained by multiplying the specific growth rate $\left(1.45 \mathrm{~d}^{-1}\right)$ by the cellular $\mathrm{N}: \mathrm{C}$ ratio $\left(0.133 \pm 0.018 \mathrm{~mol} \mathrm{~mol}^{-1} \mathrm{C}\right)$ (Tables $\left.2 \& 3\right)$. Similarly for $T$. weissflogii, the estimated $V_{\max }\left(8.07 \mathrm{~mol} \mathrm{~mol}^{-1} \mathrm{C}\right.$ $\left.\mathrm{d}^{-1}\right)$ was 62 times higher than the empirical value $(0.130$ $\pm 0.020 \mathrm{~mol} \mathrm{~mol}^{-1} \mathrm{C} \mathrm{d}^{-1}=0.87 \mathrm{~d}^{-1} \times 0.144 \pm 0.020 \mathrm{~mol}$ $\mathrm{mol}^{-1} \mathrm{C}$ ) at growth-saturating ammonium (Tables 2 \& $3)$. This high $V_{\max }$ value imposed an approximately linear fit to the observed data (Fig. 2A).

Slightly better fits were obtained from a more complex model in which a zero uptake rate occurred at a finite ammonium concentration:

$$
V= \begin{cases}V_{\max }\left(S-S_{v}\right) /\left(K_{v}+S-S_{v}\right) & \text { if } S>S_{v} \\ 0 & \text { otherwise }\end{cases}
$$

where $S_{V}$ is the ammonium level at which the uptake rate is zero. Fitting this equation to the data yielded estimates of $V_{\max }$ that were closer to the empirically measured values: 2.4-fold higher for Thalassiosira pseudonana and 4.1-fold higher for $T$. weissflogii (Table 2). To fit the data over the entire dynamic range, uptake rates were computed from Eq. (7) up to a value equal to the observed $V_{\max }$ and were then held con- 

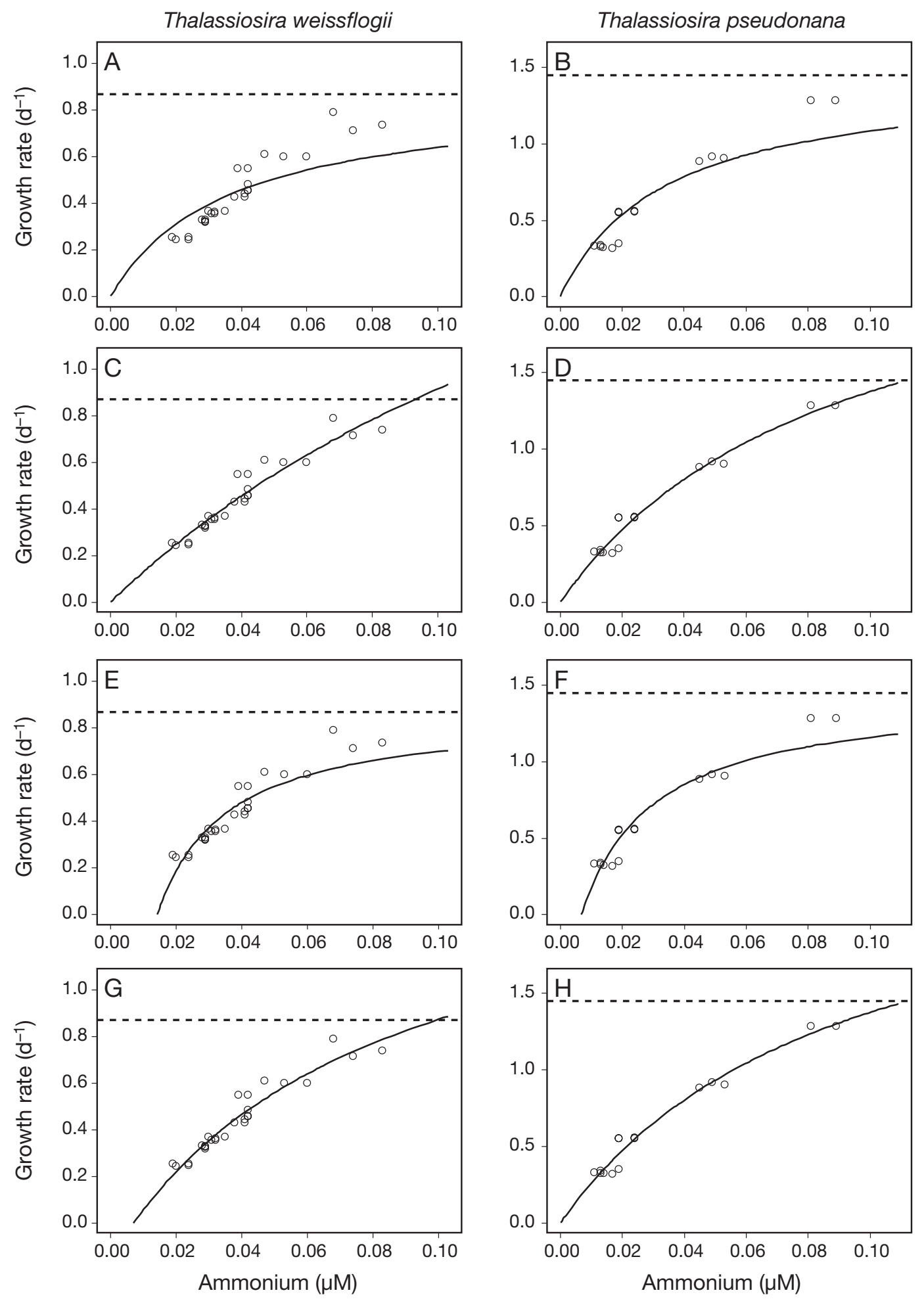

Fig. 1. Monod models for measured relationships between specific growth rate $\left(\mathrm{d}^{-1}\right)$ and ammonium concentration $(\mu \mathrm{M})$ for $(\mathrm{A}, \mathrm{C}, \mathrm{E}, \mathrm{G})$ Thalassiosira weissflogii and $(\mathrm{B}, \mathrm{D}, \mathrm{F}, \mathrm{H}) \mathrm{T}$. pseudonana. $(\mathrm{A}, \mathrm{B})$ Standard Monod model with the maximum growth rate set at the measured values ( $T$. weissflogii $0.87 \mathrm{~d}^{-1}, T$. pseudonana $\left.1.45 \mathrm{~d}^{-1}\right)$; $(\mathrm{C}, \mathrm{D})$ Monod model with a maximum growth rate estimated above the observed value; $(\mathrm{E}, \mathrm{F})$ model with the observed maximum growth rate, but with the $x$-intercept shifted to a higher finite value; $(\mathrm{G}, \mathrm{H})$ Monod model with the $x$-intercept and the maximum growth rate shifted to higher values. Parameter estimates are given in Table $1 .(\mathrm{C}, \mathrm{D}, \mathrm{G}, \mathrm{H})$ When the growth rate predicted from the model equations exceed the observed maximum value (-- -) the rate is capped at the maximum observed rate 
Table 1. Parameter estimates $\left( \pm\right.$ SE) for the classic (Eq. 1) and modified (Eq. 6) Monod models. $\mu_{\max }$ values in bold are observed maximum growth rates of Thalassiosira pseudonana and $T$. weissflogii, while plain text values are estimates from model runs where $\mu_{\max }$ was allowed to vary. Values for $K_{\mu}$ (half-saturation constant for growth) and $S_{\mu}$ (nutrient concentration at which growth is zero) were determined from the 2 sets of model runs. $\mathrm{R}^{2}$ is adjusted using the method recommended by Kvålseth (1985) to account for nonlinearity, but nonetheless should be interpreted with caution

\begin{tabular}{|c|c|c|c|c|c|}
\hline Model & Species & $\mu_{\max }\left(\mathrm{d}^{-1}\right)$ & $K_{\mu}(\mu \mathrm{M})$ & $S_{\mu}(\mu \mathrm{M})$ & Adj. $R^{2}$ \\
\hline Monod & T. pseudonana & 1.45 & $0.034 \pm 0.003$ & - & 0.859 \\
\hline Monod & T. weissflogii & 0.87 & $0.036 \pm 0.002$ & - & 0.704 \\
\hline Monod & T. pseudonana & $2.62 \pm 0.30$ & $0.091 \pm 0.016$ & - & 0.965 \\
\hline Monod & T. weissflogii & $2.79 \pm 1.08$ & $0.205 \pm 0.098$ & - & 0.911 \\
\hline Modified Monod & T. pseudonana & 1.45 & $0.023 \pm 0.003$ & $0.007 \pm 0.001$ & 0.911 \\
\hline Modified Monod & T. weissflogii & 0.87 & $0.021 \pm 0.002$ & $0.014 \pm 0.001$ & 0.844 \\
\hline Modified Monod & T. pseudonana & $2.62 \pm 0.34$ & $0.091 \pm 0.020$ & $0.000 \pm 0.001$ & 0.962 \\
\hline Modified Monod & T. weissflogii & $1.68 \pm 0.55$ & $0.087 \pm 0.052$ & $0.007 \pm 0.003$ & 0.916 \\
\hline
\end{tabular}
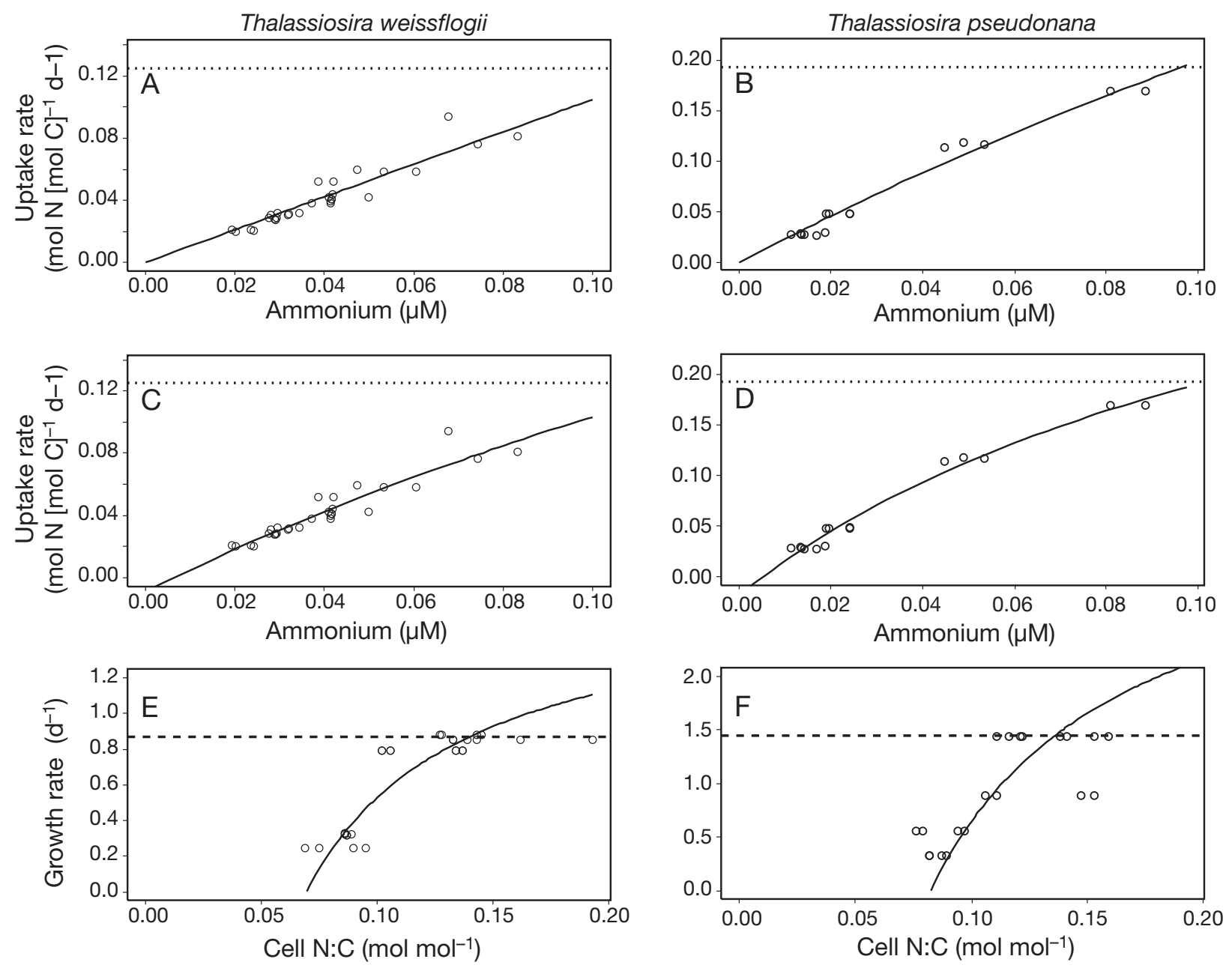

Fig. 2. Modeled relationships for nitrogen uptake rate (mol $[\mathrm{mol} \mathrm{C}]^{-1} \mathrm{~d}^{-1}$ ) versus ammonium concentration $(\mu \mathrm{M})$ and growth rate $\left(\mathrm{d}^{-1}\right)$ versus cellular $\mathrm{N}: \mathrm{C}$ molar ratio for $(\mathrm{A}, \mathrm{C}, \mathrm{E})$ Thalassiosira weissflogii and $(\mathrm{B}, \mathrm{D}, \mathrm{F}) \mathrm{T}$. pseudonana. Uptake rate data were fit to $(A, B)$ Eq. (5) and $(C, D)$ Eq. (7). Computed uptake rates greater than the observed maximum value (․) were capped at the observed maximum. (E,F) Growth rate data were fit to the standard Droop equation, capped at the observed maximum value (---) 
Table 2. Parameter estimates $( \pm \mathrm{SE})$ for the Michaelis-Menten uptake equation (Eq. 5), its modification (Eq. 7), and the Droop model (Eq. 3). The uptake parameter $V_{\max }$ is the modeled maximum uptake rate, $K_{\mathrm{V}}$ is the half-saturation constant of uptake, and $S_{V}$ is the nutrient concentration at which uptake is zero. The growth parameter $\mu_{\max }^{\prime}$ is the hypothetical maximum growth rate and $Q_{\min }$ is the cellular N:C ratio at which growth is zero, determined from data fits to the Droop equation. $\mathrm{R}^{2}$ is adjusted using the method recommended by Kvålseth (1985) to account for nonlinearity, but nonetheless should be interpreted with caution. * Parameter estimates not identifiable, as infinite sets of Michaelis-Menten parameters could provide the optimally shaped curve, which is essentially linear; thus no SE are reported. ${ }^{* *}$ Droop model parameters were estimated by inverting the equation such that $Q$ was the dependent variable; thus adjusted $\mathrm{R}^{2}$ values represent error in the $x$-direction

\begin{tabular}{|c|c|c|c|c|c|}
\hline Model & Species & $V_{\max }\left(\operatorname{mol~N}[\mathrm{mol} \mathrm{C}]^{-1} \mathrm{~d}^{-1}\right)$ & $K_{v}(\mu \mathrm{M})$ & $S_{V}(\mu \mathrm{M})$ & Adj. $R^{2}$ \\
\hline Uptake & T. pseudonana & $1.16 \pm 0.44$ & $0.483 \pm 0.212$ & - & 0.970 \\
\hline Uptake & T. weissflogii & $8.07^{*}$ & $7.59^{*}$ & - & 0.872 \\
\hline Modified uptake & T. pseudonana & $0.47 \pm 0.07$ & $0.140 \pm 0.032$ & $0.005 \pm 0.001$ & 0.977 \\
\hline Modified uptake & T. weissflogii & $0.53 \pm 0.57$ & $0.389 \pm 0.514$ & $0.006 \pm 0.003$ & 0.874 \\
\hline Model & Species & $\mu_{\max }^{\prime}\left(\mathrm{d}^{-1}\right)$ & $Q_{\min }\left(\mathrm{mol} \mathrm{N}[\mathrm{mol} \mathrm{C}]^{-1}\right)$ & & Adj. $R^{2}$ \\
\hline Droop & T. pseudonana & $3.68 \pm 0.35$ & $0.082 \pm 0.005$ & - & $0.482^{* *}$ \\
\hline Droop & T. weissflogii & $1.72 \pm 0.10$ & $0.069 \pm 0.004$ & - & $0.669^{* *}$ \\
\hline
\end{tabular}

Table 3. Thalassiosira weissflogii and T. pseudonana. Specific growth rate, mean volume per cell, cellular $\mathrm{N}$ content, cellular $\mathrm{N}$ : C ratio, and $\mathrm{N}$ per liter of cell biovolume in $\mathrm{N}$-sufficient* and $\mathrm{N}$-limited diatoms. SD are given for $\mathrm{n}$ replicate measurements. *Specific growth rate and cellular parameters measured in nutrient-saturated, semi-continuous cultures grown in medium containing initial ammonium and phosphate concentrations of 32 and $2 \mu \mathrm{M}$, respectively

\begin{tabular}{|c|c|c|c|c|c|c|}
\hline Species & Growth rate $\left(\mathrm{d}^{-1}\right)$ & Volume cell $^{-1}$ (fl) & Cell N (pmol cell-1) & $\mathrm{N}: \mathrm{C}\left(\mathrm{mmol} \mathrm{mol}{ }^{-1}\right)$ & $\mathrm{N}$ :cell volume $\left(\mathrm{mol} \mathrm{l}^{-1}\right)$ & $\mathrm{n}$ \\
\hline \multirow[t]{5}{*}{ T. weissflogii } & $0.87^{*}$ & $1056 \pm 26^{*}$ & $1.74 \pm 0.29^{*}$ & $150 \pm 23^{*}$ & $1.83 \pm 0.37$ & 6 \\
\hline & 0.88 & $635 \pm 20$ & $1.13 \pm 0.04$ & $136 \pm 9$ & $1.79 \pm 0.05$ & 4 \\
\hline & 0.79 & $540 \pm 0$ & $0.78 \pm 0.10$ & $120 \pm 18$ & $1.61 \pm 0.02$ & 4 \\
\hline & 0.33 & $545 \pm 17$ & $0.57 \pm 0.02$ & $87 \pm 1$ & $1.04 \pm 0.03$ & 6 \\
\hline & 0.25 & $540 \pm 2$ & $0.43 \pm 0.06$ & $82 \pm 12$ & $0.79 \pm 0.11$ & 4 \\
\hline \multirow[t]{4}{*}{ T. pseudonana } & $1.45^{*}$ & $58.6 \pm 3.4^{*}$ & $0.175 \pm 0.020^{*}$ & $133 \pm 18^{*}$ & $2.99 \pm 0.27^{*}$ & 6 \\
\hline & 0.88 & $50.0 \pm 1.5$ & $0.092 \pm 0.017$ & $129 \pm 24$ & $1.83 \pm 0.30$ & 4 \\
\hline & 0.55 & $41.1 \pm 0.4$ & $0.054 \pm 0.003$ & $87 \pm 11$ & $1.32 \pm 0.08$ & 4 \\
\hline & 0.32 & $42.0 \pm 1.9$ & $0.066 \pm 0.002$ & $85 \pm 4$ & $1.59 \pm 0.07$ & 4 \\
\hline
\end{tabular}

stant at that rate for all higher ammonium concentrations (Fig. 2C,D).

Relationships between specific growth rate and cellular $\mathrm{N}$ content showed reasonably good fits to the Droop equation (Eq. 3) (Fig. 2E,F). Plots of specific growth rate versus cellular $\mathrm{N}: \mathrm{C}$ ratio $(Q)$ for the 2 diatoms show steep relationships. For Thalassiosira weissflogii, there was a 1.8-fold increase in the cellular $\mathrm{N}: \mathrm{C}$ ratio between severely $\mathrm{N}$-limited cells and those growing at saturating $\mathrm{N}$, while for $T$. pseudonana this increase was 1.6-fold (Table 3). Thus $\mathrm{N}$ : C ratios in the diatoms showed only a small variation with N-limitation, as previously reported for T. pseudonana (Goldman \& McCarthy 1978).

To determine the steady-state relationships among ammonium concentrations, cellular uptake rates, cellular N:C ratios, and specific growth rates in an open continuous flow system such as a chemostat or a well- mixed lagoon, the system of differential equations (Eq. 4a-c) was solved simultaneously, with the uptake rate described by Eq. (7) and the specific growth rate by Eq. (3). The modeled relationships generated curves that closely fit the empirical data (Fig. 3A,B).

\section{Evidence for zero growth rate at finite ammonium concentrations}

The standard Monod equation and the MichaelisMenten uptake equation (Eqs. 1 \& 5, respectively) have the same mathematical form and both indicate zero growth or uptake rate at zero nutrient concentrations. Unfortunately, there is usually little actual data near zero growth rates to test this prediction, and in the case of ammonium limitation, there was essentially no published data for relationships among specific growth 

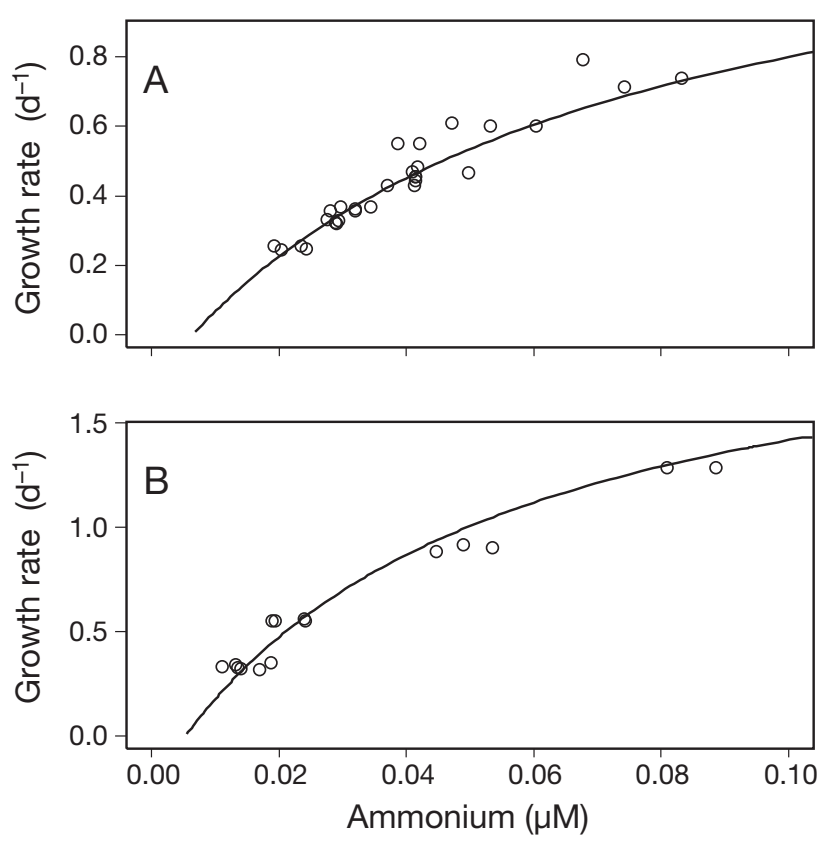

Fig. 3. Steady-state Droop-type models for growth rate $\left(\mathrm{d}^{-1}\right)$ versus ammonium concentration $(\mu \mathrm{M})$ for $(\mathrm{A})$ Thalassiosira weissflogii and (B) T. pseudonana. Model curves were generated from Eqs. (3), (4) \& (7). Uptake (see Fig. 2C,D) and growth rates (see Fig. 2E,F) were capped at their observed maxima

rate, ammonium concentration, and cellular $\mathrm{N}$ uptake rate until recently (Sunda \& Hardison 2007). As discussed above, these data suggest that zero growth rate occurs at a finite ammonium concentration as has been found previously for trace metal nutrients such as iron, zinc, and cobalt (Sunda \& Huntsman 1995a,b).

Further evidence that cells stop growing at a finite low ammonium concentration is obtained from our growth competition experiments in which Thalassiosira weissflogii (11.4 $\mu \mathrm{m}$ diameter) and 2 similarly sized dinoflagellates (Prorocentrum minimum, $13.1 \mu \mathrm{m}$, and Amphidinium carterae, $9.0 \mu \mathrm{m}$ ) were allowed to compete with a much smaller species (Aureoumbra lagunensis, $3.6 \mu \mathrm{m}$ diameter) in cyclostat cultures run at a dilution rate of $0.25 \mathrm{~d}^{-1}$. Because of its much smaller size and higher ammonium uptake rate per unit of cell biomass or biovolume, A. lagunensis should be able to outcompete the 3 larger species at the low $\mathrm{N}$-limiting dilution rate (Sunda \& Hardison 2007).

In 3 separate experiments, acclimated cultures of Aureoumbra lagunensis growing at a dilution rate of $0.25 \mathrm{~d}^{-1}$ were mixed with steady-state cultures of each of the 3 other species growing at the same dilution rate. A. lagunensis outgrew the other 3 species in all paired cyclostat experiments (Fig. 4, Table 4). In the first competition experiment, Thalassiosira weissflogii accounted for $53 \%$ of the total algal cell volume on

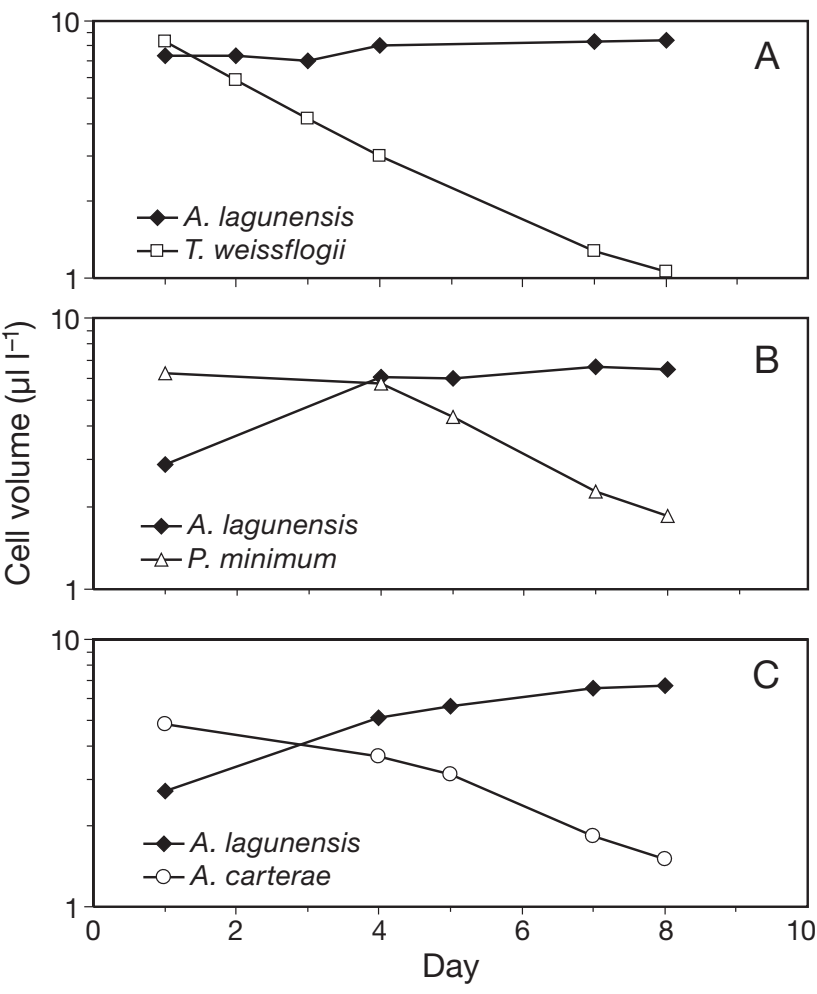

Fig. 4. Total cell biovolume versus time for competition cyclostat experiments between Aureoumbra lagunensis and 3 larger species: (A) Thalassiosira weissflogii, (B) Prorocentrum minimum, and (C) Amphidinium carterae. Experiments were conducted in ammonium-limited cyclostats at $25^{\circ} \mathrm{C}$ and a dilution rate of $0.25 \mathrm{~d}^{-1}$

Day 1, but only $11 \%$ on Day 8. Similarly, Prorocentrum minimum and Amphidinium carterae accounted for 68 and $64 \%$, respectively, of the total cellular volume on Day 1 of subsequent experiments, but only 22 and $18 \%$, respectively, on Day 8 . Thus, the smaller $A$. lagunensis was able to outcompete the 3 larger species at limiting nutrient concentrations, confirming predictions based on theory (Kiørboe 1993) and results of previous single-species cyclostat experiments with A. lagunensis and T. weissflogii (Sunda \& Hardison 2007). Indeed, once A. lagunensis became dominant (i.e. after Day 1 in the 1st experiment and Day 4 in the 2nd and 3rd experiments) and grew at a rate close to the dilution rate, the growth rate of the competing species was reduced to values near zero (Table 4), likely owing to the ability of $A$. lagunensis to drive ammonium concentrations to values low enough to prevent the growth of the competing species. In cyclostat experiments run with pure cultures of A. lagunensis at a similar dilution rate $\left(0.23 \mathrm{~d}^{-1}\right)$ and the same temperature $\left(25^{\circ} \mathrm{C}\right)$, the midday ammonium concentration in the cyclostat was $10.0 \pm 0.5 \mathrm{nM}$, a concentration at which $T$. weissflogii was estimated to have near zero growth rate (Figs. 2C \& $3 \mathrm{~A}$ ). 
Table 4. Aureoumbra lagunensis, Thalassiosira weissflogii, Prorocentrum minimum, and Amphidinium carterae. Specific growth rates and decrease in volume per cell under nutrient limitation in the 3 paired competition cyclostat experiments shown in Fig. 4. Growth rate errors are expressed as \pm SE. Errors for volume per cell are $\pm \mathrm{SD}$

\begin{tabular}{|llcccc|}
\hline Experiment & $\begin{array}{l}\text { Competing } \\
\text { species }\end{array}$ & Days & $\begin{array}{c}\text { Growth rate } \\
\left(\mathrm{d}^{-1}\right)\end{array}$ & $\begin{array}{c}\text { Volume } \\
\text { per cell (fl) }\end{array}$ & $\begin{array}{c}\text { Volume per } \\
\text { cell (nutrient } \\
\text { sufficient, fl) }\end{array}$ \\
\hline 1 & & & & $58 \pm 5$ \\
& & & & & \\
2 & A. lagunensis & $1-8$ & $0.27 \pm 0.01$ & $24 \pm 1$ & \\
& T. weissflogii & & $-0.05 \pm 0.01$ & $784 \pm 32$ & $1316 \pm 62$ \\
& A. lagunensis & $1-4$ & 0.50 & & \\
& P. minimum & & 0.22 & & $58 \pm 5$ \\
& A. lagunensis & $4-8$ & $0.27 \pm 0.01$ & $25 \pm 1$ & $1234 \pm 79$ \\
& P. minimum & & $-0.04 \pm 0.01$ & $1190 \pm 41$ & \\
& A. lagunensis & $1-4$ & 0.47 & & $58 \pm 5$ \\
& A. carterae & & 0.16 & & \\
& A. lagunensis & $4-8$ & $0.32 \pm 0.01$ & $23 \pm 1$ & \\
& A. carterae & & $0.02 \pm 0.01$ & $382 \pm 17$ & $760 \pm 41$ \\
& & & & & \\
\end{tabular}

The ability of Aureoumbra lagunensis to outcompete the other species could result in part from an extracellular release of toxic (allelopathic) compounds that inhibited the growth of competing algae. To test this possibility, the cyclostat culture containing Thalassiosira weissflogii and A. lagunensis in the 1st experiment was diluted by 17 -fold on Day 8 into fresh media containing a 2.7-fold higher ammonium concentration $(32 \mu \mathrm{M})$ and an N:P ratio of 16 . Successive dilutions were then made on Days 6 and 10 to prevent the cells from substantially depleting the nutrients in the medium. Following the first dilution, T. weissflogii began growing at a rate exceeding that of A. lagunensis after only a $1 \mathrm{~d}$ lag (Fig. 5). On Day 1 of the experiment, $T$. weissflogii accounted for only $10 \%$ of the cell volume, but 12 d later it was the dominant alga and represented $81 \%$ of the total cell volume. The growth rates of the 2 species under nutrient sufficiency on Days 7 to 13 $\left(1.27 \mathrm{~d}^{-1}\right.$ for $T$. weissflogii and $0.73 \mathrm{~d}^{-1}$ for A. lagunensis) equaled those for the species cultured individually in semi-continuous cultures under nutrient sufficiency, arguing against the release of allelopathic compounds by either alga.

$\mathrm{N}$ limitation in the cyclostats was accompanied by a substantial reduction in volume per cell in 3 of the 4 species (Table 4). The largest volume reduction (59\%) was observed for Aureoumbra lagunensis, while Amphidinium carterae and Thalassiosira weissflogii each showed somewhat smaller reductions (50 and $40 \%$, respectively) in volume per cell. The decrease in volume helps the cells acclimate to limiting nutrient concentrations by decreasing surface to volume ratios and the thickness of the cell's diffusive boundary layer (Sunda \& Hardison 2007). However, it also complicates nutrient uptake models for marine phytoplankton (Flynn 2008).

\section{Model simulations of nutrient and population dynamics}

The Monod and Droop modeling approaches yielded similarly good fits to our measured steady-state relationships between N-limited growth rate and ammonium concentration. However, in time-course simulations of hypothetical continuous flow algal systems, the 2 modeling approaches predicted different transient dynamics in response to a 2 -fold step increase in influent ammonium concentration (Fig. 6). Moreover, the relative magnitude of the differences was sensitive to the dilution rate of the system $\left(0.2\right.$ versus $\left.0.6 \mathrm{~d}^{-1}\right)$. Following the step increase in influent ammonium, there was an instantaneous increase in the predicted ammonium concentration in the model systems, which was larger in the Monod type model, especially at the higher dilution rate (Fig. 6A,B). The larger increase in ammonium concentration in the Monod model is linked to differences in

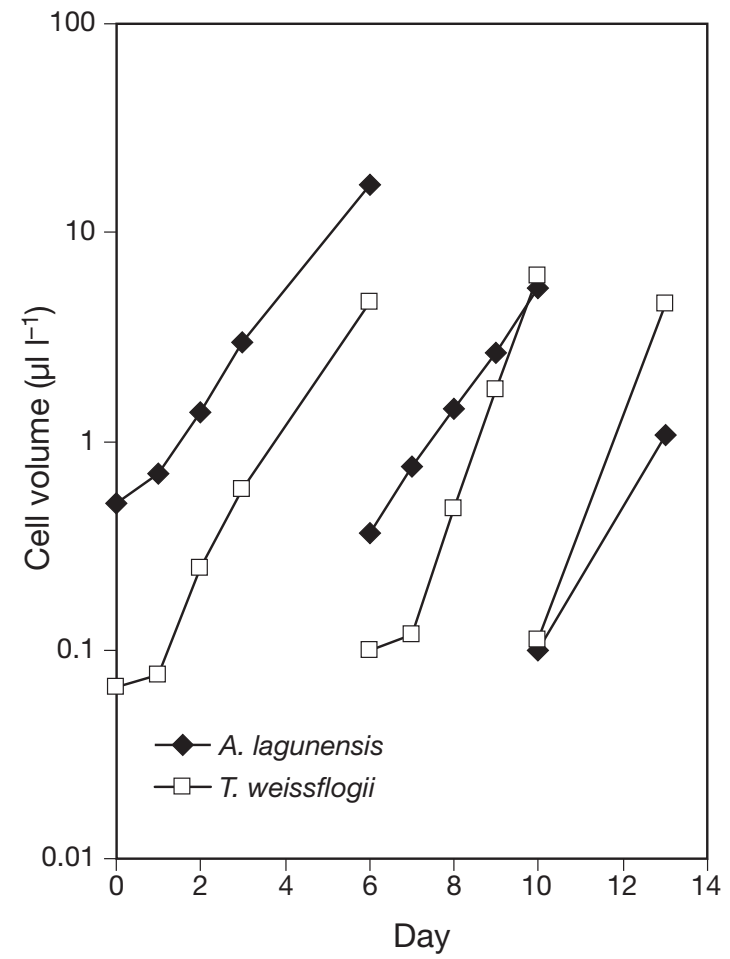

Fig. 5. Growth competition experiment between Aureoumbra lagunensis and Thalassiosira weissflogii under nutrient-sufficient conditions in semi-continuous batch cultures containing $32 \mu \mathrm{M}$ ammonium and $2 \mu \mathrm{M}$ phosphate. The cells were transferred into the new medium on Day 8 of the cyclostat competition experiment (Fig. 4A) and were transferred serially on Days 6 and 10 

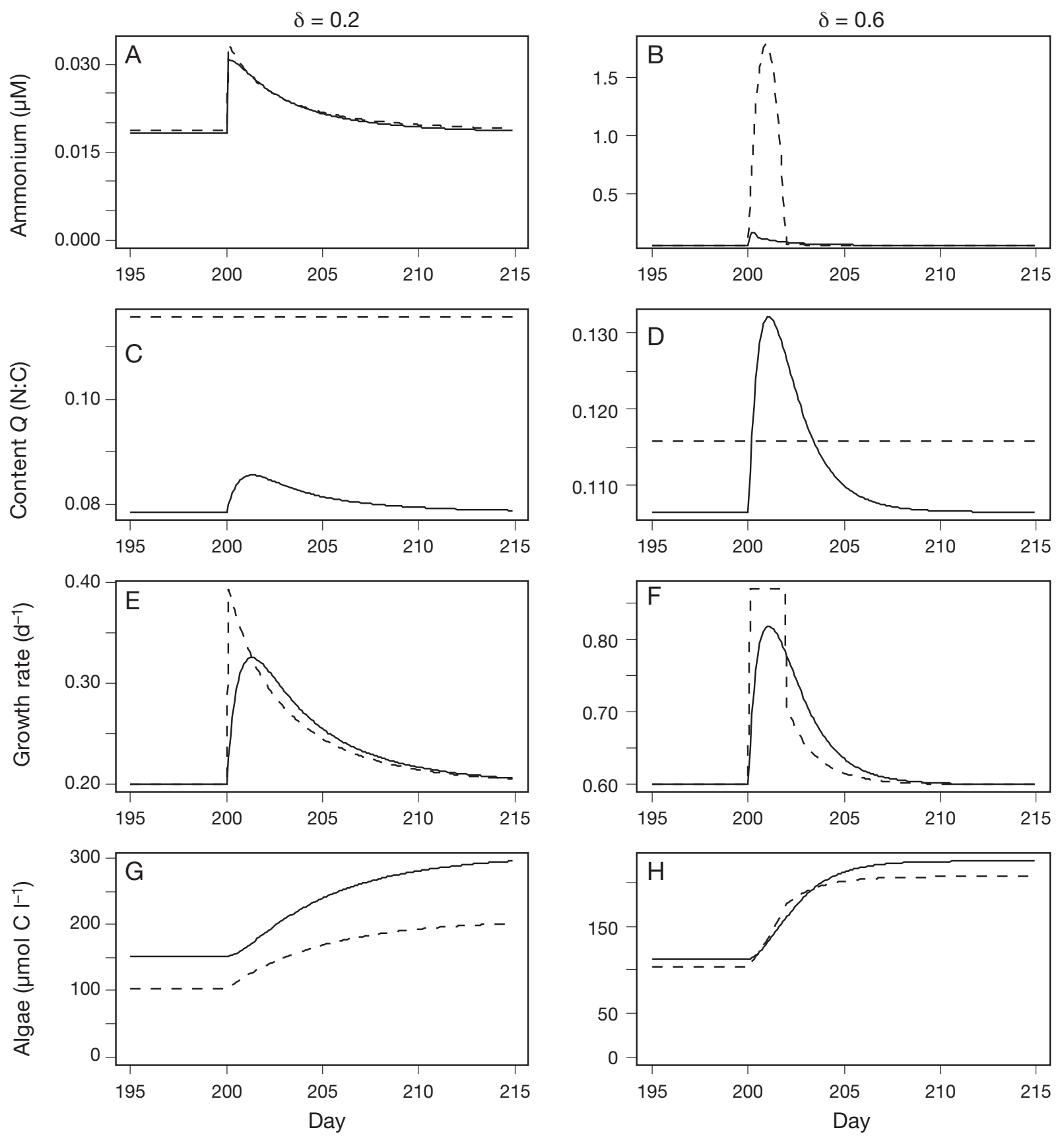

Fig. 6. Simulations of time-dependent responses of steady-state cyclostat cultures of Thalassiosira weissflogii to a step increase in ammonium concentration from 12 to $24 \mu \mathrm{M}$. Comparisons are made between predictions from the modified Monod (---) and Droop models (-). Predictions are given for time-dependent changes in $(A, B)$ ambient ammonium concentration $(\mu M)$; $(C, D)$ cellular N:C molar ratio $(Q) ;(E, F)$ specific algal growth rate; and $(\mathrm{G}, \mathrm{H})$ total concentration of algal $\mathrm{C}$ (mol C $\left.\mathrm{l}^{-1} \mathrm{medium}\right)$. Results are given for both low $\left(0.2 \mathrm{~d}^{-1}\right.$, left panels) and high $\left(0.6 \mathrm{~d}^{-1}\right.$, right panels) dilution rates. Scale of $y$-axes differs across panels

the $\mathrm{N}$ content of the cells between the 2 models. In the Droop model, $\mathrm{N}$ content per cell increased with increasing nutrient concentration in the water, whereas in the Monod model the $\mathrm{N}$ content is fixed (Fig. 6C,D). This increase in $\mathrm{N}$ content of the cells in the Droop model results in a faster and larger drawdown of the increased ammonium concentration back toward the steady-state value. There were also differences in growth rate behavior following the step increase in inflowing ammonium. In the Monod model, growth rate depends directly on the external nutrient concentration (Eq. 1), and thus the sharp rise in ammonium con- 
centration in the growth chamber (Fig. 6A,B) translated immediately into a spike in growth rate. However, in the Droop model, growth rate is linked to the nutrient content per cell, which increased only gradually (Fig. 6C,D). Thus, the changes in growth rate were smaller, more gradual, and delayed in the Droop-type model (Fig. 6E,F).

The final difference in the behavior of the 2 models was a difference in the predicted amount of cell carbon per liter of seawater medium, which varied with dilution rate (Fig. 6G,H). These variations result from the differences in the cellular N:C ratio, which was allowed to vary in the Droop model and but was held constant in Monod (Flynn 2005). Such differences can have dramatic effects on the behavior of food web models where the feeding and growth of herbivores depends directly on the concentration of total algal $\mathrm{C}$ available for consumption. Thus, the predicted population dynamics of herbivores could depend on the choice of Monod or Droop modeling approaches because of differences in predicted prey quality $(\mathrm{N}$ : $\mathrm{C}$ molar ratio) and concentration of consumable cell $\mathrm{C}$.

\section{DISCUSSION}

\section{Lack of fit to standard equations}

Our results show that both the Monod and Droop approaches can be used to model steady-state relationships between nutrients and specific growth rates of the diatoms Thalassiosira pseudonana and T. weissflogii; however, the classic Monod growth equation and the Michaelis-Menten uptake equation had to be modified to obtain reasonable fits to the observed data. The lack of an exact fit to the standard Monod equation is not surprising as that equation was empirically derived to fit data for steady-state relationships between the specific growth rate of bacteria and the concentration of organic growth substrates (Monod 1949). Thus, there is no a priori reason that this equation would also describe the relationships between the growth rate of algal photoautotrophs and the concentration of limiting inorganic nutrients. Indeed, if we look at measured relationships between the specific growth of algal species and concentrations of limiting micronutrient metals ( $\mathrm{Fe}, \mathrm{Zn}, \mathrm{Co}$, and $\mathrm{Mn}$ ), we typically do not see a good fit with the standard Monod model, and often see curves that differ in shape depending on the metal nutrient, the algal species, and experimental conditions (e.g. light, $\mathrm{CO}_{2}$, and co-limiting nutrients) (Sunda \& Huntsman 1995a,b, 2005). In the present study, the relationship between $\mathrm{N}$-limited specific growth rates and ammonium concentrations was steeper than predicted from the Monod equation, but this difficulty was overcome by increasing the $V_{\max }$ in the equation to above the observed value and then capping the growth rate at the empirical maximum value at high ammonium concentrations.

In our Droop type models, there was a reasonably good fit to the standard Droop equation, but this equation already allows one to artificially set the maximum growth rate in the equation to any number between the empirically observed value and infinity, which provides a mechanism to control the steepness of modeled curves (Goldman \& McCarthy 1978). The Droop approach also requires the development of a mathematical relationship for nutrient uptake rate as a function of the nutrient concentration. The traditional model used is the Michaelis-Menten equation, which predicts the theoretical rate of nutrient uptake into a cell by a membrane transport protein present at a fixed concentration. However, in reality the concentration of membrane transport proteins (and thus the $V_{\text {max }}$ of the system) is under negative feedback regulation, and consequently changes substantially with the intracellular nutrient status for virtually all nutrients, including ammonium, nitrate, phosphate and all trace metals examined to date (Gotham \& Rhee 1981a, b, Goldman \& Glibert 1982, Sunda \& Huntsman 1986, 1992, Flynn et al. 1999). Thus, the Michaelis-Menten equation would not necessarily be expected to describe the relationship between uptake rate of acclimated algal cells and the external nutrient concentration. A second difficulty is that the uptake rate can be limited by the diffusion of the nutrient to the cell surface, which is not taken into account in the standard Michaelis-Menten equation (Pasciak \& Gavis 1974). For Thalassiosira weissflogii, ammonium uptake rates were 50 to $80 \%$ of the maximum limiting rate of ammonium diffusion to the cell surface (Sunda \& Hardison 2007), explaining why the uptake was essentially linearly related to the ammonium concentration. Diffusion limitation decreases with decreasing cell size, and for the smaller T. pseudonana $(4.5 \mu \mathrm{m}$ diameter), uptake rates were only $\sim 40 \%$ of the limiting diffusion rate. This lessening of diffusion as a controlling factor may help explain the more curvilinear uptake behavior for this species. In our models, we were able to accommodate the variable shape of the uptake curves by allowing the maximum uptake rate to exceed the empirically observed value, which provided greater linearity to the curves. To prevent the modeled uptake rates from exceeding the empirically observed maximum rate, we capped the rates at the observed maximum value at high concentrations whenever the computed rate exceeded the empirical maximum rate.

A second change we made to the standard Michaelis-Menten equation was to shift the $x$-intercept 
from the origin to a finite positive value. This modification results in a final steady-state model in which growth ceases not at zero substrate, but at some finite concentration (Fig. 5). Although this modification is unusual for nutrient uptake models, it is supported by empirical evidence for ammonium and for other limiting nutrients and algal resources. The first line of supporting evidence is the near-zero growth rates observed for the 3 larger species (Thalassiosira weissflogii, Amphidinium carterae, and Prorocentrum minimum) when these species were competed with the much smaller species (Aureoumbra lagunensis) in ammonium-limited cyclostat cultures. At the low dilution rate of $0.25 \mathrm{~d}^{-1}$, the smaller species reduced the ammonium concentration to ca. $10 \mathrm{nM}$ (Sunda \& Hardison 2007), which appeared to be too low to allow growth of the larger species. Similar results have been observed in competition experiments between 2 small diatoms Skeletonema costatum and Chaetoceros septentrionalis and the much larger diatom Thalassiosira gravida in ammonium-limited chemostats (Mickelson et al. 1979). As in our experiments, each of the smaller species outgrew the larger one under ammonium limitation; and once it became dominant, it drove ammonium concentrations to a sufficiently low level to stop the growth of the large diatom.

A second line of evidence is our inability to establish steady-state cyclostat cultures at very low dilution rates and associated low ammonium concentrations (W. G. Sunda \& D. R. Hardison unpubl. data). In our cyclostat culture studies we progressively decreased the dilution rates (and thus the specific growth rate of the algae), but when the dilution rate was decreased below $\sim 20 \%$ of the maximum growth rate, the cyclostat became unstable and the cells washed out of the system. Similar instabilities have been observed previously at very low specific growth rates (below $20 \%$ of maximum) in ammonium-limited continuous cultures, including those with Thalassiosira weissflogii, and were accompanied by an abrupt large decrease in maximum ammonium uptake rates (Goldman \& Glibert 1982). These effects may have been caused by a lack of sufficient cellular energy to maintain a high capacity uptake system at very low specific rates of photosynthesis and growth. However, they also may have been caused by the formation of asexual or sexual cellular resting spores, which are known to be induced under severe nutrient limitation (French \& Hargraves 1980).

The above findings are consistent with those for trace metal nutrient limitation of marine phytoplankton in trace metal ion buffer systems, which do not require the establishment of steady-state growth conditions. In studies with $\mathrm{Fe}, \mathrm{Zn}$, and Co limitation of growth rate of Thalassiosira pseudonana, T. weiss- flogii, and other species, there was usually a concentration of available inorganic nutrient metal at which the growth rate was reduced to zero (Sunda \& Huntsman 1995a,b, 2005). Such findings are in line with limitation by other resources such as light, where there is a finite light intensity below which net photosynthesis and growth ceases. A similar phenomenon occurs for zooplankton growth as a function of the concentration of food organisms, where the zooplankton cease feeding at food levels below some critical value (Leising et al. 2003).

\section{Implications for ecosystem modeling}

Both our modified Monod and Droop modeling approaches accurately described the observed relationships between specific growth rates and ammonium concentrations under acclimated, steady-state conditions. Thus if that is all one wanted to do, then the Monod model is clearly preferred as it is simpler and requires less computing time and measurement of model parameters, which could become important if included as part of a much more complex ecosystem model involving diverse arrays of algal species. However, the 2 approaches predict different transient dynamics (Flynn 2005). The Monod model does a poor job of predicting algal growth under changing nutrient conditions because it assumes that the specific growth rate responds instantaneously to the external nutrient concentration, which clearly is not the case (Grover 1991). In addition, it cannot be used to accurately predict $\mathrm{C}$ assimilation by animal grazers or $\mathrm{C}$ transfer to the sediments or aphotic depths from plankton settling because such predictions require knowledge of the nutrient to C ratio of algal cells (Sterner \& Elser 2002, Mitra et al. 2007). One could estimate this by assuming some average cellular $\mathrm{C}$ to nutrient ratio, but again, this assumption does not reconcile the observed variation in cell quota with varying nutrient concentration. Although the Droop modeling approach is much more complex and requires the determination of many more model parameters, this complexity allows one to more accurately predict the complex time-dependent changes in algal populations and $\mathrm{C}$ fixation with changing nutrient concentrations. Thus, this modeling approach is preferred in food web models used to predict algal blooms, $\mathrm{C}$ cycling, and other nonequilibrium dynamics of ecosystems.

Acknowledgements. We thank W. Litaker, R. Waggett, and 2 anonymous reviewers for helpful comments. K.W.S. is grateful for the support of NOAA's Southeast Fisheries Science Center. The opinions expressed are those of the authors and do not necessarily reflect policies of any government agency. 


\section{LITERATURE CITED}

Droop MR (1968) Vitamin B12 and marine ecology. IV. The kinetics of growth and inhibition in Monochrysis lutheri. J Mar Biol Assoc UK 48:689-733

Falkowski PG, Raven JA (1997) Aquatic photosynthesis. Blackwell Science, Malden, MA

Flynn KJ (2005) Modelling marine phytoplankton growth under eutrophic conditions. J Sea Res 54:92-103

Flynn KJ (2008) Use, abuse, misconceptions and insights from quota models: the Droop cell quota model 40 years on. Oceanogr Mar Biol Annu Rev 46:1-23

Flynn KJ, Page S, Wood G, Hipkin CR (1999) Variations in the maximum transport rates for ammonium and nitrate in the prymnesiophyte Emiliania huxleyi and the raphidophyte Heterosigma carterae. J Plankton Res 21:355-371

French FW, Hargraves PE (1980) Physiological characteristics of plankton diatom resting spores. Mar Biol Lett 1:185-195

Frost BW, Franzen NC (1992) Grazing and iron limitation in control of phytoplankton stock and nutrient concentration: a chemostat analogue of the Pacific equatorial upwelling zone. Mar Ecol Prog Ser 83:291-303

Fussmann GF, Ellner SP, Shertzer KW, Hairston NG Jr (2000) Crossing the Hopf bifurcation in a live predator-prey system. Science 290:1358-1360

Goldman JC (1977) Steady state growth of phytoplankton in continuous culture: comparison of internal and external nutrient equations. J Phycol 13:251-258

Goldman JC, Glibert PM (1982) Comparative rapid ammonium uptake by four species of marine phytoplankton. Limnol Oceanogr 27:814-827

Goldman JC, McCarthy JJ (1978) Steady state growth and ammonium uptake of a fast-growing marine diatom. Limnol Oceanogr 23:695-703

Gotham IJ, Rhee GY (1981a) Comparative kinetic studies of phosphate-limited growth and phosphate uptake in phytoplankton in continuous culture. J Phycol 17:257-265

Gotham IJ, Rhee GY (1981b) Comparative kinetic studies of nitrate-limited growth and nitrate uptake in phytoplankton in continuous culture. J Phycol 17:309-314

Grover JP (1991) Dynamics of competition among microalgae in variable environments: experimental tests of alternative models. Oikos 62:231-243

Haefner JW (2005) Modeling biological systems: principles and applications, 2nd edn. Springer, New York

Harrison WG, Harris LR, Irwin BD (1996) The kinetics of nitrogen utilization in the oceanic mixed layer: nitrate and ammonium interactions at nanomolar concentrations. Limnol Oceanogr 41:16-32

Kilham P, Hecky RE (1988) Comparative ecology of marine and freshwater phytoplankton. Limnol Oceanogr 33:776-795

Kiørboe T (1993) Turbulence, phytoplankton cell size, and the structure of pelagic food webs. Adv Mar Biol 29:1-72

Kvålseth TO (1985) Cautionary note about $R^{2}$. Am Stat 39: 279-285

Leising AW, Wendy C, Gentleman WC, Frost BW (2003) The threshold feeding response of microzooplankton within

Editorial responsibility: Matthias Seaman, Oldendorf/Luhe, Germany
Pacific high-nitrate low-chlorophyll ecosystem models under steady and variable iron input. Deep-Sea Res II 50: 2877-2894

Mickelson MJ, Maske H, Dugdale RC (1979) Nutrient determined dominance in multispecies chemostat cultures of diatoms. Limnol Oceanogr 24:298-315

> Mitra A, Flynn KJ (2006) Promotion of harmful algal blooms by zooplankton predatory activity. Biol Lett 2:194-197

Mitra A, Flynn KJ, Fasham MJR (2007) Accounting for grazing dynamics in nitrogen-phytoplankton-zooplankton models. Limnol Oceanogr 52:649-661

Monod J (1942) La croissance des cultures bacteriennes. Herman, Paris

> Monod J (1949) The growth of bacterial cultures. Annu Rev Microbiol 3:371-394

Moore CM, Mills MM, Langlois R, Milne A, Achterberg EP, La Roche J, Geider RJ (2008) Relative influence of nitrogen and phosphorus availability on phytoplankton physiology and productivity in the oligotrophic sub-tropical North Atlantic Ocean. Limnol Oceanogr 53:291-305

Morel FMM (1987) Kinetics of nutrient uptake and growth in phytoplankton. J Phycol 23:137-150

Mulholland M, Lomas M (2008) Nitrogen uptake and assimilation. In: Capone DG, Bronk DA, Mulholland MR, Carpenter EJ (eds) Nitrogen in the marine environment. Elsevier, Amsterdam, p 293-374

Pasciak WJ, Gavis J (1974) Transport limitation of nutrient uptake in phytoplankton. Limnol Oceanogr 19:881-888

R Development Core Team (2008) R: a language and environment for statistical computing. R Foundation for Statistical Computing, Vienna, available at www.R-project.org

Ryther JH (1969) Photosynthesis and fish production in the sea. Science 166:72-76

Sterner RW, Elser JJ (2002) Ecological stoichiometry. Princeton University Press, Princeton, NJ

Sunda WG, Hardison DR (2007) Ammonium uptake and growth limitation in marine phytoplankton. Limnol Oceanogr 52:2496-2506

> Sunda WG, Huntsman SA (1986) Relationships among growth rate, cellular manganese concentrations and manganese transport kinetics in estuarine and oceanic species of the diatom Thalassiosira. J Phycol 22:259-270

Sunda WG, Huntsman SA (1992) Feedback interactions between zinc and phytoplankton in seawater. Limnol Oceanogr 37:25-40

Sunda WG, Huntsman SA (1995a) Iron uptake and growth limitation in oceanic and coastal phytoplankton. Mar Chem 50:189-206

Sunda WG, Huntsman SA (1995b) Cobalt and zinc interreplacement in marine phytoplankton: Biological and geochemical implications. Limnol Oceanogr 40:1404-1417

Sunda WG, Huntsman SA (2005) Effect of $\mathrm{CO}_{2}$ supply and demand on zinc uptake and growth limitation in a coastal diatom. Limnol Oceanogr 50:1181-1192

> Sunda WG, Graneli E, Gobler CJ (2006) Positive feedback and the development and persistence of ecosystem disruptive algal blooms. J Phycol 42:963-974

Submitted: November 17,2008; Accepted: April 21, 2009 Proofs received from author(s): June 24, 2009 